Article

\title{
Synthesis of a Novel Catalyst MnO/CNTs for Microwave-Induced Degradation of Tetracycline
}

\author{
Tianming Liu ${ }^{1}$, Guobao Yuan ${ }^{1}$, Guocheng $\operatorname{Lv}^{1}{ }^{1}{ }^{*}$, Yuxin Li $^{1}$, Libing Liao ${ }^{1}$, , Siyao Qiu ${ }^{2}$ and \\ Chenghua Sun $2,3, *$ \\ 1 Beijing Key Laboratory of Materials Utilization of Nonmetallic Minerals and Solid Wastes, National \\ Laboratory of Mineral Materials, School of Materials Science and Technology, China University of \\ Geosciences, Beijing 100083, China; tianmingliu@cugb.edu.cn (T.L.); SY1927205@buaa.edu.cn (G.Y.); \\ yuxinli@cugb.edu.cn (Y.L.) \\ 2 Department of Chemistry and Biotechnology, and Center for Translational Atomaterials, Swinburne \\ University of Technology, Hawthorn, VIC 3122, Australia; qsy333666@163.com \\ 3 School of Chemical Engineering and Energy Technology, Dongguan University of Technology, \\ Dongguan 523808, China \\ * Correspondence: guochenglv@cugb.edu.cn (G.L.); clayl@cugb.edu.cn (L.L.); \\ chenghuaSun@swin.edu.au (C.S.); Tel.: +86-10-82322759 (G.L.); +86-10-82321701 (L.L.); \\ $+61-3-9214-5059$ (C.S.)
}

Received: 15 October 2019; Accepted: 28 October 2019; Published: 30 October 2019

\begin{abstract}
Microwave-induced catalytic degradation (MICD) has been considered as one of the most prospective approaches to remove organic contaminants from water. High-performance catalysts, ideally offering efficient degradation ability, are essential to this process. This work reports the fabrication of manganese oxide on carbon nanotubes (MnO/CNTs) as an efficient catalyst under microwave irradiation (MI) to remove tetracycline (TC) from aqueous solution. The hybrid MnO/CNTs structure shows excellent performance in TC degradation. Combining experimental characterization and theoretical calculations, synergistic mechanisms are revealed: (i) Strong MnO/CNTs interaction stabilizes Mn(II) through interfacial bonding; (ii) high-spin states associated with low coordinated $\mathrm{Mn}(\mathrm{II})$ play a major role in MICD; and (iii) superoxide radicals $\left(\bullet \mathrm{O}_{2}{ }^{-}\right)$and hydroxyl radicals $(\bullet \mathrm{OH})$ induced by microwave input are identified as the major active species.
\end{abstract}

Keywords: microwave-induced; manganese oxide; catalysts; tetracycline; degradation

\section{Introduction}

The development and application of antibiotics is one of the greatest successes of medical science in the 20th century for its excellent effect in controlling and treating infectious diseases [1-3]. However, many antibiotics are not easily absorbed and digested but are excreted in the form of feces or urine [4]. As a result, they have been widely detected in the environment (soil, lakes, and even drinking water) [3-5]. Antibiotic residues in the environment can cause bacterial resistance, which seriously threatens human health and ecosystem balance [4-6]. Therefore, it is necessary to develop innovative and effective technologies to degrade antibiotics from contaminated water to minimize ecological risks.

Tetracycline (TC), one of the most common antibiotics discovered in water, is widely used to treat bacterial infections [3,4]. According to a survey, most sewage treatment plants do not have the function of removing microorganisms currently, and most TC or other antibiotics are discharged without specific treatment [6,7]. Although common physical or physicochemical methods have the ability to adsorb and reduce TC, concentrated TC still needs further processing. Currently, there are many treatment technologies for sewage containing antibiotics, including sorption and biodegradation [8]; electrochemical-advanced oxidation [9]; $\mathrm{ZnO-,} \mathrm{Bi2O3-,} \mathrm{CdO-,} \mathrm{and} \mathrm{TiO2-enhanced}$ 
photocatalytic degradation [10-13]; and membrane bioreactors [14]. Nevertheless, these methods still have disadvantages, such as a high price, long processing cycle, and so on. Compared with other methods, microwave-induced catalytic degradation has the advantages of a short reaction time, high reaction rate, and low energy consumption [15-17]. Under irradiation, appropriate microwave absorbing materials are used to decompose organic contaminants, such as Congo red [18], rhodamine B [19], and methylene blue [20], with no side effects [21,22], which plays a very important role in MICD [23,24].

Recently, metal nanoparticles/carbon nanotube (CNT) composites with ideal microwave absorption properties have been reported $[25,26]$. The interfacial polarization, dipole polarization, and electronic transitions in the CNT conductive network have a positive effect on dielectric loss [27]. Natural resonance and exchange resonance of metal nanoparticles increase magnetic loss [28]. With such a synergistic effect, these composites are expected to be candidate catalysts for MICD. For example, Yin and coworkers reported that $\mathrm{Co} / \mathrm{CNTs}$ exhibits a good microwave absorption performance because of multiple microwave reflection and scattering and good impedance matching [29]. The $\mathrm{Fe}_{3} \mathrm{O}_{4} / \mathrm{CNT}$ composites reported by $\mathrm{Li}$ and colleagues improve microwave absorption by effectively compensating for dielectric and magnetic losses [30]. Under MI, metal nanoparticles/CNTs composites convert electromagnetic energy into thermal energy because of dielectric and magnetic losses, and the generated thermal energy accelerates the degradation of organic contaminants [31]. We previously reported the use of $\mathrm{Fe}_{3} \mathrm{O}_{4} / \mathrm{CNTs}$ in MICD [32], where Fe has a mixed valence state. When the total number of unpaired electrons in the central ion is high, this causes a large spin magnetic moment, and a stronger response to the microwave [17,33]. Therefore, the outermost electron configuration of $\mathrm{Mn}$ (II) in the high-spin states is $3 \mathrm{~d}^{5}$, and there are more unpaired electrons, which could play a key role in microwave absorption [24]. To date, designing MICD catalysts that meet the absorption frequency and degradation efficiency remains a challenge.

In this work, $\mathrm{MnO} / \mathrm{CNTs}$ nanocomposite as MICD catalysts was synthesized by an ordinary and effective way of refluxing and calcining (Figure 1). CNTs were first oxidized to increase the hydroxyl and carboxyl groups, resulting in increased negative charges of the surface of CNTs. Manganese ions with positive charge were drawn to the surface of CNTs by electrostatic interaction. MnO grains were further grown during a solvothermal process. CNTs may contribute to the stabilization of $\mathrm{MnO}$, which has been studied in previous studies [34]. Any excess manganese ions were removed by subsequent washing, which helps to maintain the particle size in the range of 3 to $8 \mathrm{~nm}$. Strong interaction exists between $\mathrm{MnO}$ and CNTs, which promotes catalyst regeneration and prolongs the catalyst's lifespan. The microwave catalytic performance of $\mathrm{MnO} / \mathrm{CNTs}$ was evaluated with TC as the target containment. The experimental results show that $\mathrm{MnO} / \mathrm{CNTs}$ composite can effectively remove TC during the MICD process. The degradation mechanism was proposed and verified by theoretical calculations.

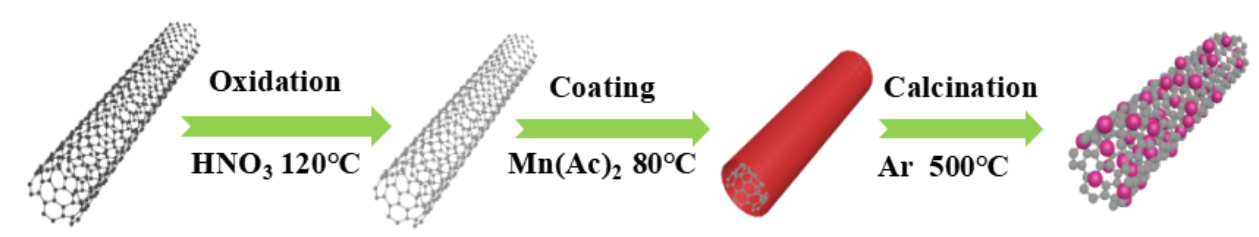
Carbon nanotubes
Oxidized CNTs
$\mathrm{Mn}(\mathrm{Ac}) \mathrm{OH} / \mathrm{CNTs}$
MnO/CNTs (CNTs)

Figure 1. Schematic demonstration of the fabrication of MnO/CNTs composites. 


\section{Results and Discussion}

\subsection{Characterization of $\mathrm{MnO} / \mathrm{CNTS}$}

XRD patterns of the synthesized $\mathrm{Mn}(\mathrm{Ac}) \mathrm{OH} / \mathrm{CNTs}$ (precursor), $\mathrm{MnO} / \mathrm{CNTs}$, and MnO/CNTs after degradation are shown in Figure 2. Broad characteristic peaks of CNTs at $\sim 26^{\circ}$ can be seen in the XRD patterns of $\mathrm{Mn}(\mathrm{Ac}) \mathrm{OH} / \mathrm{CNTs}$ and $\mathrm{MnO} / \mathrm{CNTs}$. The remaining $\mathrm{MnO} / \mathrm{CNTs}$ diffraction peaks match well with the face-centered cubic MnO (JCPDS 75-625) located at 34.9, 40.5, and 58.7 ${ }^{\circ}$ with corresponding indices (111), (200), and (220). In addition, there were no other crystal phase characteristic peaks, indicating that the sample was of high purity. After $30 \mathrm{~min}$ of reaction, the XRD patterns of MnO/CNTs showed no significant change in the intensity of the diffraction peak during the catalytic reaction. A small peak appeared at about $36^{\circ}$, which is possibly a general slight broadening of the oxide reflections. Furthermore, the results of ICP-AES (Table S1) demonstrated that no manganese was present in the degraded solution, confirming the stability of $\mathrm{MnO} / \mathrm{CNT}$ as the TC degradation catalyst.

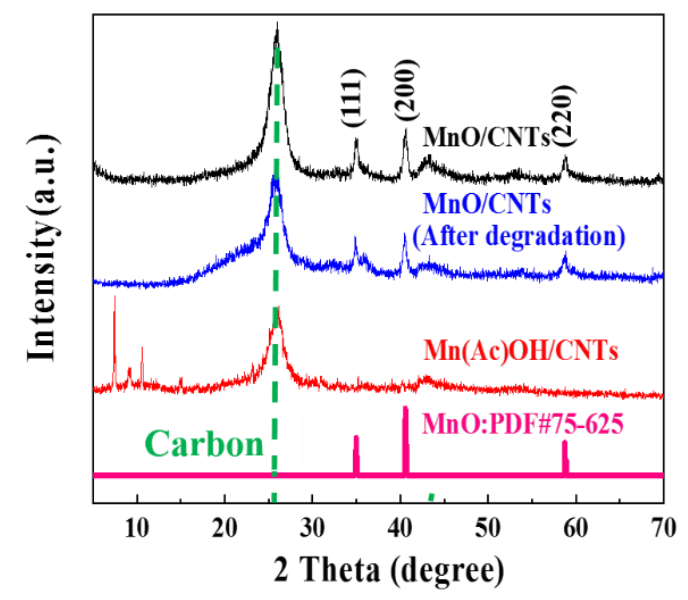

Figure 2. Structural characterization. X-ray diffraction patterns of $\mathrm{Mn}(\mathrm{Ac}) \mathrm{OH} / \mathrm{CNTs}, \mathrm{MnO} / \mathrm{CNTs}$, and $\mathrm{MnO} / \mathrm{CNTs}$ after TC degradation under MI.

TEM images of the oxidized CNTs and $\mathrm{Mn}(\mathrm{Ac}) \mathrm{OH} / \mathrm{CNTs}$ are displayed in Figure 3a,b, respectively. It can be observed that the wall of CNTs coated with manganese hydroxy acetic acid was thicker than the pristine ones, which could be attributed to the homogeneous coating of manganese hydroxy acetic acid on the surface of CNTs. The EDS patterns in Figure 3e confirm the uniformity of the manganese hydroxy acetic acid coating. TEM images of MnO/CNTs in Figure 3c clearly show that the $\mathrm{MnO}$ nanoparticles are coated on the CNTs, and the MnO nanoparticles have a diameter of 3 to 8 $\mathrm{nm}$. The high-resolution TEM images (Figure 3d) further demonstrate a lattice spacing of $0.227 \mathrm{~nm}$, corresponding to the (200) crystal plane of MnO. The EDS pattern of MnO/CNTs in Figure $3 \mathrm{f}$ confirms the $\mathrm{MnO}$ nanoparticles are supported on the CNTs.

The chemical composition and elemental oxidation states of the composites were investigated by XPS because they are strongly correlated to stability. All peaks were corrected by C1's peaks position at $284.4 \mathrm{eV}$ [35]. As shown in Figure $4 \mathrm{a}$, the full spectrum of $\mathrm{MnO} / \mathrm{CNTs}$ and MnO/CNTs after TC degradation under MI revealed the existence of manganese (Mn 2p, $641.2 \mathrm{eV})$, carbon (C 1s, 284.4 eV), and oxygen $(\mathrm{O} 1 \mathrm{~s}, 532 \mathrm{eV})$, which agreed well with the EDS data. The C1's XPS spectrum (Figure 4b) showed three different peaks at 284.4, 286.1, and $288.8 \mathrm{eV}$, corresponding to C-C, C-O, and C = O bonds [36,37], respectively. As shown in Figure 4c, the O1's XPS spectrum showed three different peaks at $530.1(\mathrm{Mn}-\mathrm{O}), 531.8(\mathrm{C}-\mathrm{O})$, and $533.2 \mathrm{eV}(\mathrm{C}=\mathrm{O})$ [38,39]. MnO/CNTs (Figure 4b) and MnO/CNTs after TC degradation under MI (Figure 4c) were both analyzed by XPS spectra, and the separation between $\mathrm{Mn} 2 \mathrm{p}_{1 / 2}(652.8 \mathrm{eV})$ and $\mathrm{Mn} 2 \mathrm{p}_{3 / 2}(641.2 \mathrm{eV})$ was found to be $11.6 \mathrm{eV}$, which agrees with the characteristics of $\mathrm{MnO}[40,41]$. The valence state of Mn did not change during the MICD process, which further indicates the stability of the composites. 

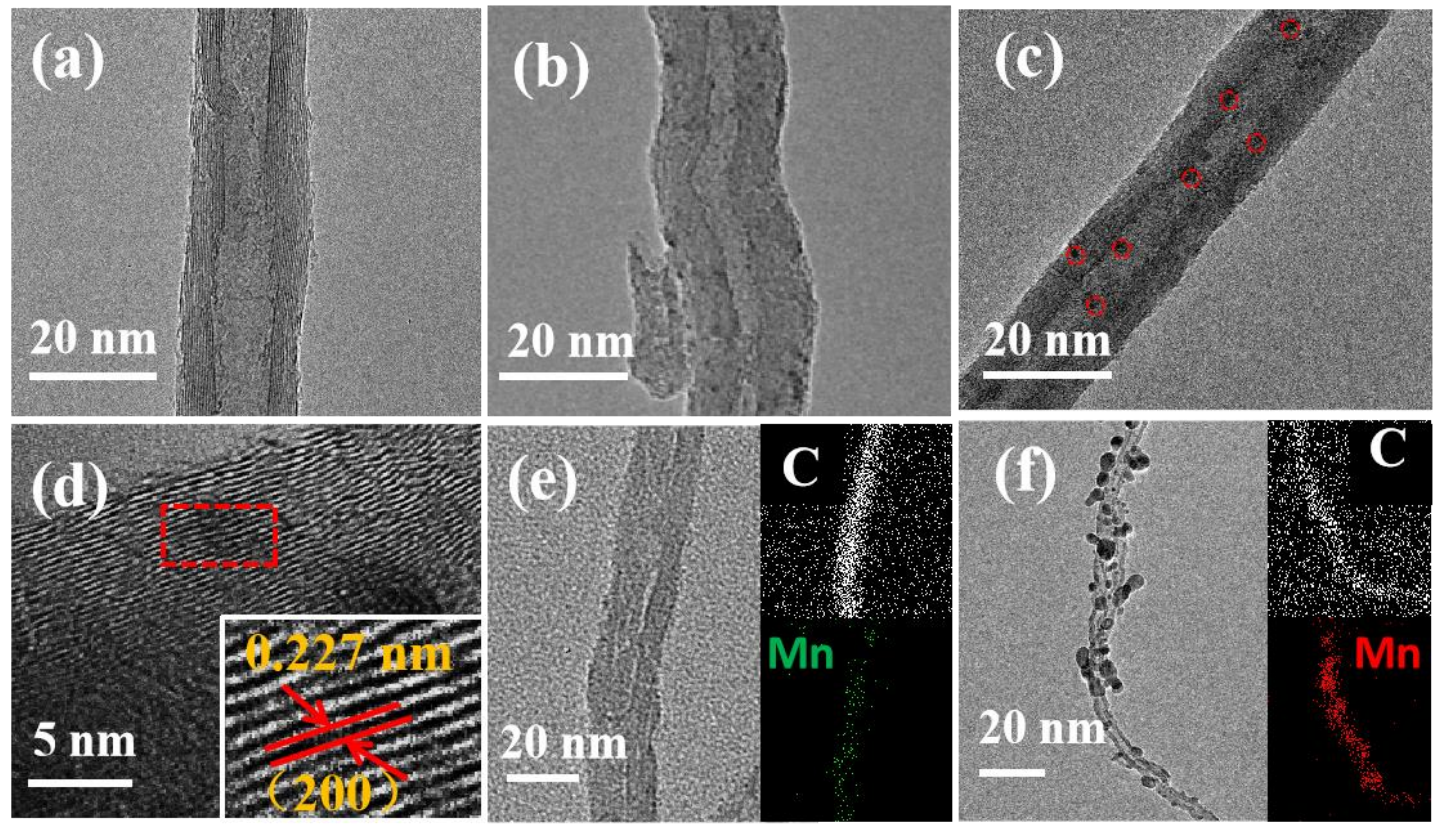

Figure 3. TEM image of oxidized CNTs (a) Mn(Ac)OH/CNTs (b), MnO/CNTs (c), HRTEM image of $\mathrm{MnO} / \mathrm{CNTs}$ using the fast Fourier transform (FFT) (d), and EDS element mapping images of $\mathrm{Mn}(\mathrm{Ac}) \mathrm{OH} / \mathrm{CNTs}(\mathbf{e})$ and $\mathrm{MnO} / \mathrm{CNTs}(\mathbf{f})$.
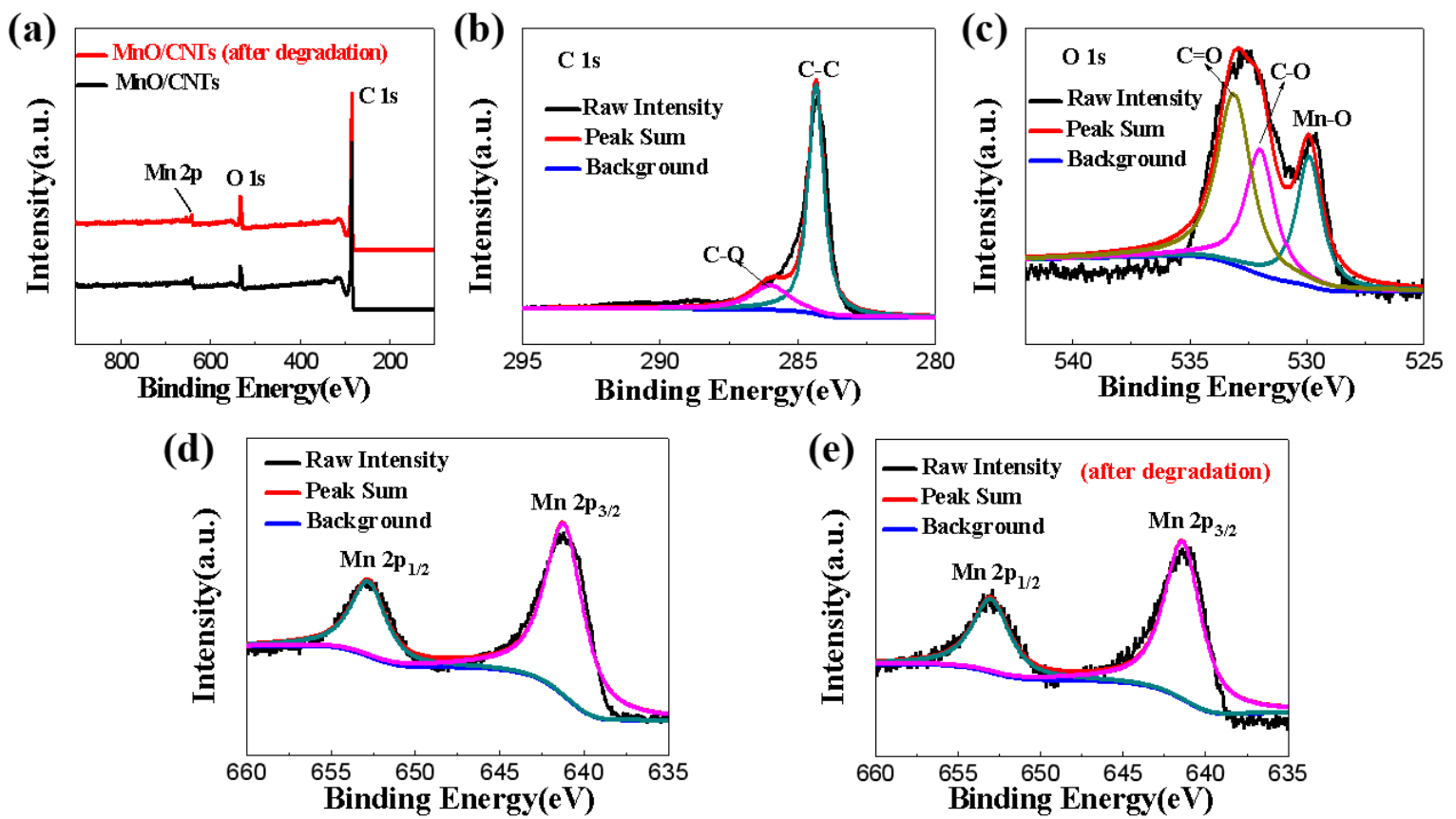

Figure 4. XPS study. (a) Full survey of MnO/CNTs and MnO/CNTs after TC degradation under MI, and high-resolution XPS spectra: $\mathrm{C}$ 1s of MnO/CNTs (b), O 1s of MnO/CNTs (c), Mn 2p of MnO/CNTs (d), and Mn $2 \mathrm{p}$ of MnO/CNTs after TC degradation under MI (e).

\subsection{TC Removal by $\mathrm{MnO} / \mathrm{CNTS}$}

In view of the unique hybrid structure of $\mathrm{MnO} / \mathrm{CNTs}$, we utilized it as a microwave catalyst to remove TC. Although pure microwave irradiation and thtte $\mathrm{MnO} / \mathrm{CNTs}+$ shaking system could partially remove $\mathrm{TC}$, the combination of $\mathrm{MnO} / \mathrm{CNTs}+\mathrm{MI}$ systems resulted in a much better performance as demonstrated in Figure 5a. In a typical run, the highest TC removal amount of MnO/CNTs within $10 \mathrm{~min}$ under MI reached $185.7 \mathrm{mg} / \mathrm{g}$, and the removal efficiency of TC increased to $95 \%$ within 
30 minutes under MI. To verify the synergistic effect of $\mathrm{MnO}$ and CNTs in the composite, we performed experiments on the degradation of TC by MnO and CNTs in the presence of MI, respectively (Figure 5a). The results show that the $\mathrm{MnO} / \mathrm{CNTs}$ composites have a much higher degradation efficiency than the single component catalysts, which further confirms the improvement of the degradation performance of the $\mathrm{MnO} / \mathrm{CNTS}$ composites. Pure microwave degradation and MICD both followed a pseudo second-order dynamics model as recorded by UV spectrophotometry (Figure $5 b$ ). When the catalyst was applied to the solution, the reaction kinetic coefficient of the MICD process $\left(\mathrm{k}_{1}=0.0530\right)$ was about six times higher than that when no catalyst was present $\left(k_{2}=0.0093\right)$. As described in Table S2, such degradation kinetics were much higher than other antibiotic removal methods reported in the literature.

(a)

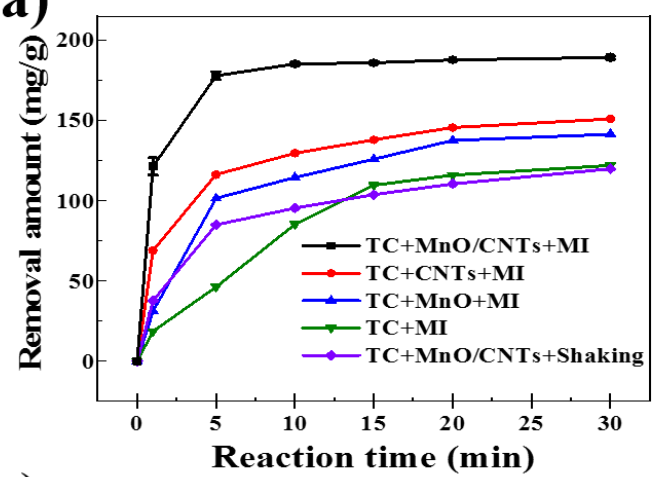

(c)

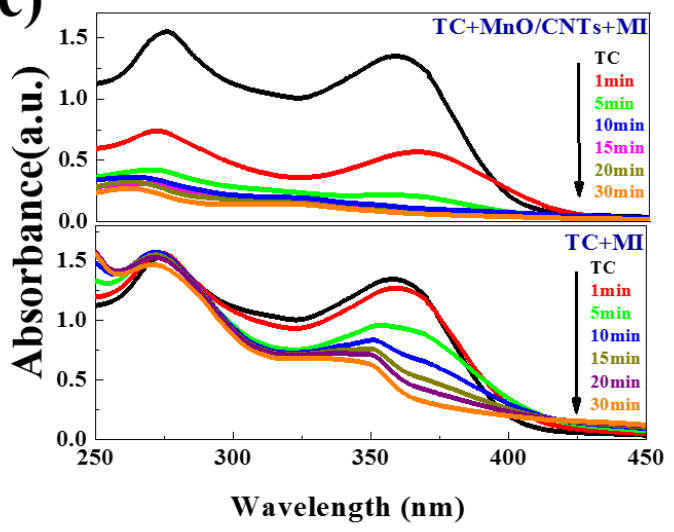

(b)

(d)
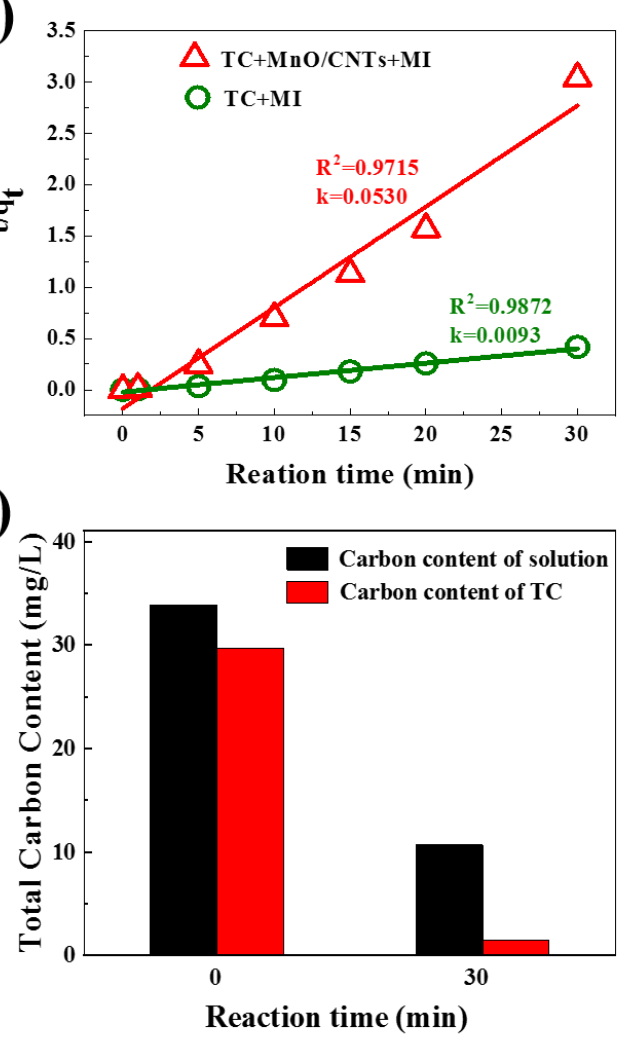

Figure 5. Removal of TC in the presence and absence of microwave and MnO/CNTs (a), pseudo-second-order degradation kinetic plots of TC (b), UV/Vis spectra of TC solution with/without $\mathrm{MnO} / \mathrm{CNTs}$ after MI for different times (c), and and total carbon content with MnO/CNTs in the presence of the microwave $(\mathbf{d})$.

After microwave irradiation, the TC concentration was characterized by UV-Vis spectroscopy. As can be seen from Figure $5 c$, as the microwave time increases, the intensity of the TC absorption peak at $365 \mathrm{~nm}$ decreases. The absorption peak disappeared completely when the reaction time reached 30 minutes. The TCC value in the solution dropped significantly after $30 \mathrm{~min}$ of microwave and catalyst interaction (Figure 5d), indicating the generation and discharge of carbon gas, such as carbon dioxide. The carbon content of TC in the solution also decreased significantly and was lower than that of TCC, indicating that TC was decomposed into small organic molecules and inorganic carbon gases.

To further investigate the behavior of $\mathrm{MnO} / \mathrm{CNTs}$ during the MICD process, the effects of the initial concentration of TC, initial $\mathrm{pH}$, and microwave power on degradation were also studied. As shown in Figure 6a, as the concentration of TC increases, the extent of degradation decreases. The removal amount of TC was as high as $190 \mathrm{mg} / \mathrm{g}$ after $30 \mathrm{~min}$ under $700 \mathrm{~W}$, but the TC removal amount dropped to $175 \mathrm{mg} / \mathrm{g}$ when the microwave power was reduced to $300 \mathrm{~W}$ (Figure 6b). This is because more 
energy input will regenerate more "hot spots" [40-43] on the external MnO/CNTs, which improves the production of active substances and accelerates the decomposition of TC. Therefore, in consideration of degradation efficiency, an output power of $700 \mathrm{~W}$ was selected in the subsequent experiments. TC has different $\mathrm{pK}_{\mathrm{a}}$ values: $\mathrm{pK}_{\mathrm{a} 1}=3.3, \mathrm{pK}_{\mathrm{a} 2}=7.7$, and $\mathrm{pK}_{\mathrm{a} 3}=9.7$ [44]. The TC of different functional groups will be ionized under different $\mathrm{pH}$ conditions, resulting in different amounts of charge. Monovalent cations were the predominant form when the $\mathrm{pH}$ was less than 3.3 or greater than 7.7. Neutral molecules were the predominant form when the $\mathrm{pH}$ was between 3.3 and 7.7. The formation of dianion was dominant when the $\mathrm{pH}$ was greater than $9.3[44,45]$. The experimental results in Figure $6 \mathrm{c}$ indicate the removal efficiency of TC was better under acid conditions. When the $\mathrm{pH}$ value of the solution increased above 7.0, the degradation efficiency was remarkably reduced. The optimum $\mathrm{pH}$ value for TC degradation was 1, and the removal rate of TC could reach $98 \%$ under MI of 30 min. These results are similar to a previous work [46]. It is worth noting that such catalyst has excellent durability, as shown in Figure 6d, where a continuous slight decrease is observed over five reaction cycles. Since the catalyst was repeatedly used during the experiment process, a small quantity of the mass was lost after centrifugation and the drying process, but the cycle efficiency was maintained. In addition, it should be noted that CNTs are biologically toxic, so the catalyst should be recovered after the degradation reaction [47].

(a)

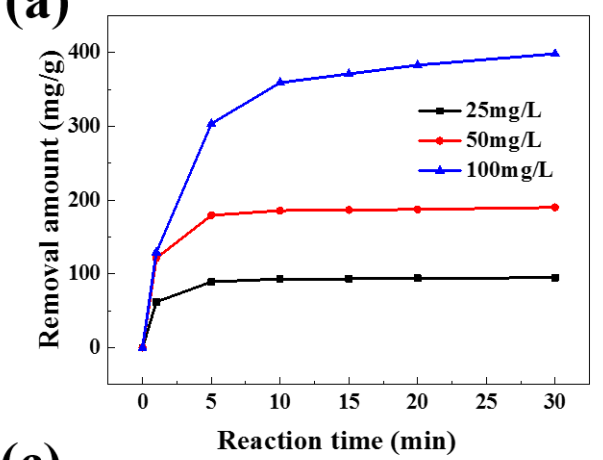

(c)

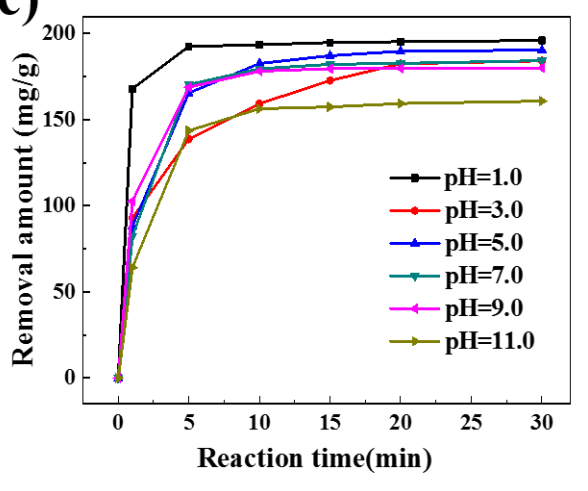

(b)

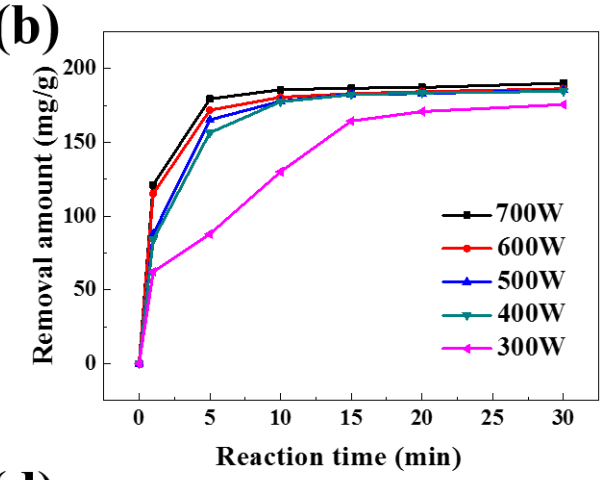

(d)

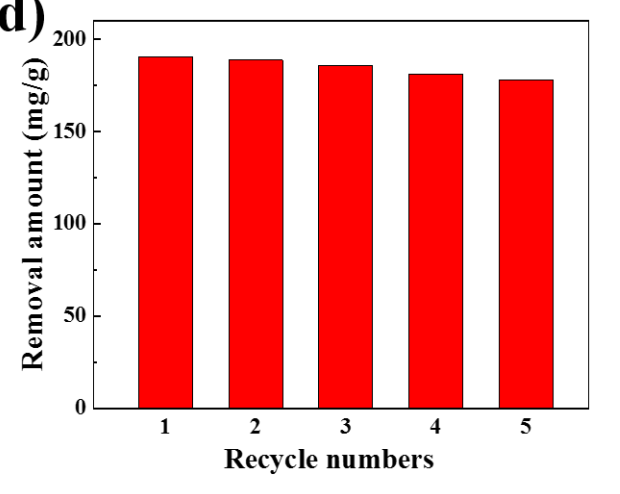

Figure 6. Effect of the initial concentration of TC (a), microwave power (b), and solution $\mathrm{pH}(\mathbf{c})$ on the degradation of TC, and cycle stability test for MnO/CNTs (d).

\subsection{Possible Mechanism of Catalytic Degradation}

It is generally believed that numerous reactive species, such as $\bullet \mathrm{O}_{2}{ }^{-}$and $\bullet \mathrm{OH}$, play a significant role in the decomposition process of TC [48-50]. There are a lot of "hot spots" on the surface of CNTs under MI. Generally speaking, the temperature of "hot spots" could reach $120{ }^{\circ} \mathrm{C}$ or higher [40-43]. In this case, the TC molecules could be directly decomposed (or pyrolyzed) under the influence of high temperatures. The introduction of $\mathrm{MnO}$ nanoparticles promotes the generation of "hot spots", which will be discussed in future theoretical calculations. Electrons on the CNTs could be transferred to the $\mathrm{Mn}-\mathrm{O}$ through the $\mathrm{C}-\mathrm{O}$ bond and the $\mathrm{C}=\mathrm{O}$ bond channel, so the $\mathrm{Mn}^{2+}$ in the $\mathrm{MnO}$ was not oxidized 
under $\mathrm{MI}$, thereby maintaining the stability of $\mathrm{MnO} / \mathrm{CNTs}$ during the MICD process. Furthermore, the $\mathrm{H}_{2} \mathrm{O}$ molecules around the "hot spot" were spit into hydroxyl radicals $(\bullet \mathrm{OH})$ and hydrogen radicals $(\bullet \mathrm{H})$. The oxygen $\left(\mathrm{O}_{2}\right)$ adsorbed on the catalyst surface reacted with $\bullet \mathrm{H}$ to generate superoxide radical anion $\left(\bullet \mathrm{O}_{2}{ }^{-}\right)$, which could further react with water to generate $\bullet \mathrm{OH}$. Then, $\bullet \mathrm{OH}$ and $\bullet \mathrm{O}_{2}{ }^{-}$reacted with the active center of TC to convert to $\mathrm{CO}_{2}, \mathrm{H}_{2} \mathrm{O}$, and some simple inorganic ions [51]. The above reaction process can be described as the following equations (Equations (1)-(4)):

$$
\begin{gathered}
\mathrm{H}_{2} \mathrm{O}(\mathrm{MI}) \rightarrow \bullet \mathrm{OH}+\bullet \mathrm{H}, \\
2 \bullet \mathrm{H}+2 \mathrm{O}_{2} \rightarrow \bullet \mathrm{O}_{2}^{-}+2 \bullet \mathrm{OH}, \\
2 \bullet \mathrm{O}_{2}^{-}+2 \mathrm{H}_{2} \mathrm{O} \rightarrow 2 \bullet \mathrm{OH}+2 \mathrm{OH}^{-}+\mathrm{O}_{2}, \\
\bullet \mathrm{OH}+\bullet \mathrm{O}_{2}^{-}+\mathrm{TC} \rightarrow \mathrm{CO}_{2}, \mathrm{H}_{2} \mathrm{O} \text { and inorganic ions. }
\end{gathered}
$$

Scavenger molecule tests were performed to further study the effects of $\bullet \mathrm{OH}$ and $\bullet \mathrm{O}_{2}{ }^{-}$radicals on the degradation performance of TC. We added isopropanol (IPA) to the TC solution as a scavenger for $\bullet \mathrm{OH}$. Similarly, benzoquinone (BQ) was added as a scavenger for $\bullet \mathrm{O}_{2}{ }^{-}$in another group of experiments [52]. The equilibrium concentration of TC after microwave treatment was determined by a UV-vis spectrophotometer. As shown in Figure 7a, the degradation efficiency of TC was significantly decreased after adding the scavenger. The removal amount of TC decreased from 190 to $176 \mathrm{mg} / \mathrm{g}$ after adding IPA within $30 \mathrm{~min}$. However, the removal amount of TC decreased to $143 \mathrm{mg} / \mathrm{g}$ when $\mathrm{BQ}$ was added to the solution. It can be seen that $\bullet \mathrm{O}_{2}{ }^{-}$was the primary active substance during the MICD process of TC. These scavenger tests further demonstrated that $\bullet \mathrm{OH}$ and $\bullet \mathrm{O}_{2}{ }^{-}$are primarily responsible for TC degradation [53].
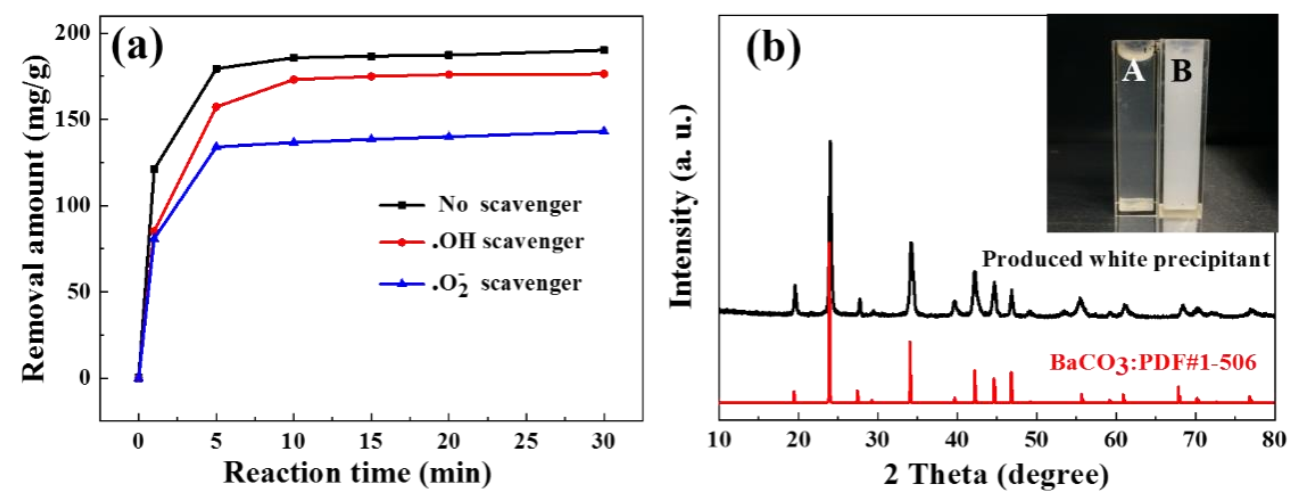

Figure 7. The effects of scavengers on the degradation of TC with MnO/CNTs under MI (a); XRD patterns of the white precipitation formed in $\mathrm{Ba}(\mathrm{OH})_{2}$ solutions $(\mathbf{b})$. Insert: picture of $\mathrm{Ba}(\mathrm{OH})_{2}$ solutions after treatment. Gas produced by only $\mathrm{H}_{2} \mathrm{O}$ with $\mathrm{MI}(\mathrm{A})$ and gas produced by TC degradation with $\mathrm{MI}$ (B) passed through $\mathrm{Ba}(\mathrm{OH})_{2}$ solutions.

In order to further investigate the enhanced TC degradation by catalyst under MI, the pristine TC solution (Figure 8a), TC solution under MI only (Figure 8b), and TC solution under MI and catalyst (Figure $8 \mathrm{c}, \mathrm{d}$ ) were analyzed by HPLC-MS. For pristine TC, its MS results are shown in Figure S1, and the $\mathrm{m} / \mathrm{z}$ value of 445 corresponds to $\mathrm{C}_{22} \mathrm{H}_{25} \mathrm{~N}_{2} \mathrm{O}_{8}$ or protonated TC. It can be seen that there were a number of relatively large molecular weight compounds present during microwave treatment only, as identified by the MS results in Figure S2. The results indicated that MI could decompose a small amount of TC in the absence of catalyst. The $\mathrm{m} / \mathrm{z}$ values of the compounds were $384,400,417$, and 427 , and the corresponding molecular formulas were predicted to be $\mathrm{C}_{21} \mathrm{H}_{22} \mathrm{NO}_{6}, \mathrm{C}_{21} \mathrm{H}_{22} \mathrm{NO}_{7}, \mathrm{C}_{21} \mathrm{H}_{25} \mathrm{~N}_{2} \mathrm{O}_{7}$, and $\mathrm{C}_{22} \mathrm{H}_{23} \mathrm{~N}_{2} \mathrm{O}_{7}$. HPLC-MS analysis showed that the fragments of TC produced compound ions with $\mathrm{m} / \mathrm{z}=417$ due to the loss of $\mathrm{CO}$. Additionally, the compound ions with $\mathrm{m} / \mathrm{z}=400$ were further fragmented due to the loss of $\mathrm{NH}_{3}$. Furthermore, the compound ions with $\mathrm{m} / \mathrm{z}=384$ were fragmented 
due to the loss of $\mathrm{H}_{2} \mathrm{O}$. The HPLC-MS spectrum of TC solution after 10 and 30 min under MI in the presence of $\mathrm{MnO} / \mathrm{CNTs}$ catalyst are displayed in Figure 8c,d, respectively. It was found that only a small amount of degradation products could be discovered within 10 min under MI with the presence of MnO/CNTs catalyst, and Figure S3 shows the corresponding MS results. However, no significant intermediate could be observed under MI for $0.5 \mathrm{~h}$. The results showed that TC completely decomposed in the presence of MI and catalyst in less than $30 \mathrm{~min}$. Thus, it can be concluded that the MICD process involves the production of a series of small molecular weight organic compounds that are ultimately degraded to $\mathrm{CO}_{2}, \mathrm{H}_{2} \mathrm{O}$, and inorganic ions [51].
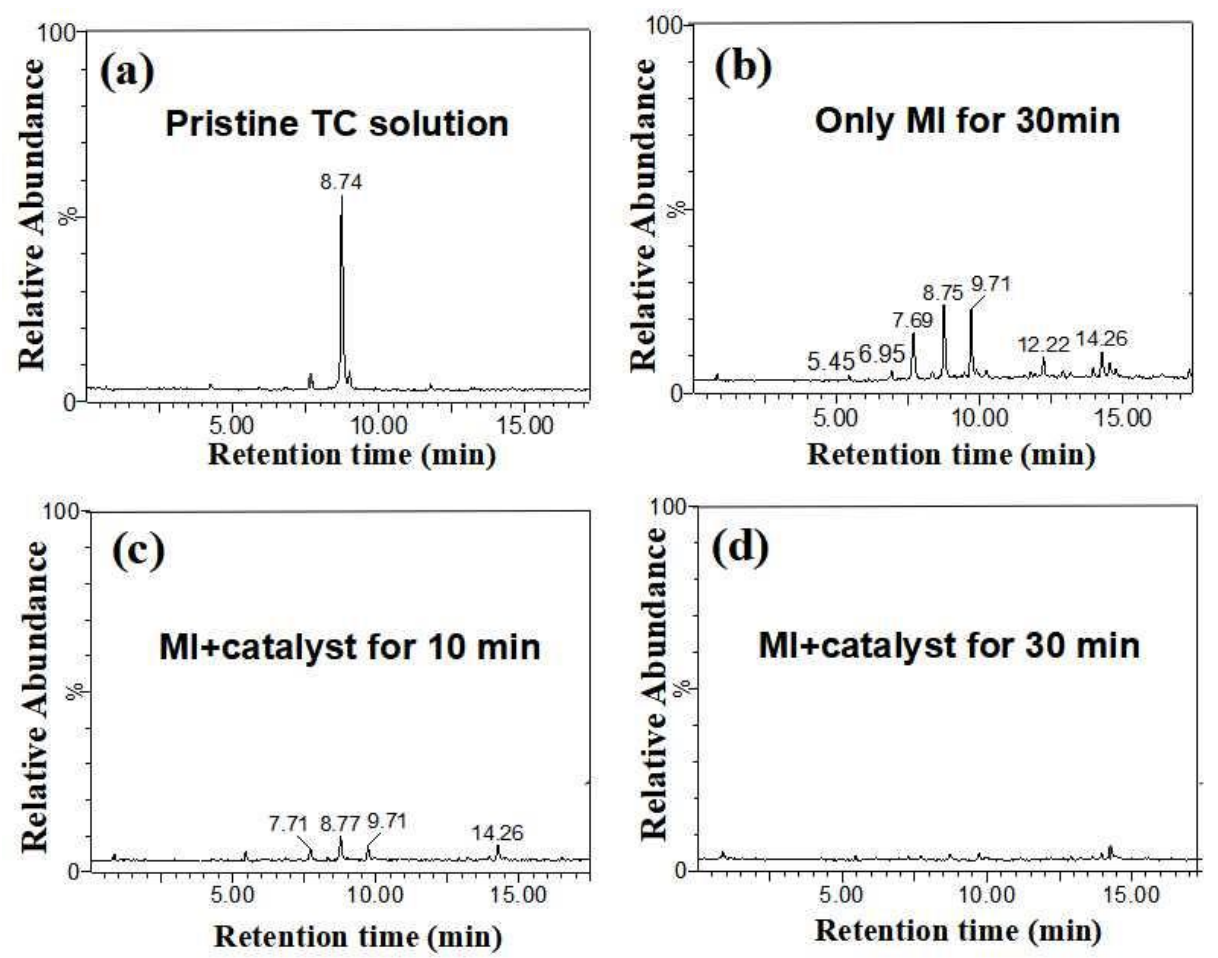

Figure 8. High-performance liquid chromatography of TC (a), TC under MI for $30 \mathrm{~min}(\mathbf{b})$, and TC under $\mathrm{MI}$ using $\mathrm{MnO} / \mathrm{CNTs}$ as catalyst for 10 (c) and $30 \mathrm{~min}(\mathbf{d})$.

The final degradation products of TC were further investigated by subsequent experiments. The gas produced during the MICD process was passed through $50 \mathrm{~mL}$ of saturated barium hydroxide solution. The results showed that the solution became turbid, and white precipitate formed (Figure $7 \mathrm{~b}$ illustration) on the bottom of the vessel. In contrast, there was no obvious precipitation in the control experiment when TC was not added to the solution. The white precipitate was confirmed to be $\mathrm{BaCO}_{3}$ by XRD analysis (Figure $7 \mathrm{~b}$ ). Therefore, it can be concluded that the produced gas contains carbon dioxide. The TC solution before and after degradation under MI was also analyzed by IC (Table S3). The results showed that the degradation solution contained $\mathrm{NO}_{3}{ }^{-}$. Therefore, we propose the overall degradation reaction equation as follows:

$$
\mathrm{C}_{22} \mathrm{H}_{24} \mathrm{~N}_{2} \mathrm{O}_{8}+\mathrm{O}_{2} \rightarrow \mathrm{CO}_{2}+\mathrm{NO}_{3}^{-}+\mathrm{H}_{2} \mathrm{O} .
$$

\subsection{Roles of CNTs and $\mathrm{MnO}$ Components}

As evidenced from the degradation tests, the $\mathrm{MnO} / \mathrm{CNTs}$ hybrid structure has the best performance under microwave irradiation, although it is worth clarifying whether $\mathrm{MnO}$ can strengthen such degradation. In principle, $\mathrm{Mn}$ (II) shows a high-spin state when coordinated with a weak ligand, as schematically shown in Figure $9 a$, where both the $e_{g}$ and $t_{2 g}$ states were partially occupied by unpaired electrons. To clarify the role of $\mathrm{MnO}$, an adsorption model for TC on $\mathrm{MnO}$ was built and optimized, as 
shown in Figure 9b, where CNTs were modified with graphene layers because the curvature effect can be ignored for large-diameter CNTs. Accordingly, the adsorption energy of TC on the MnO cluster is $1.29 \mathrm{eV}$, which is slightly higher than that on graphene $(1.08 \mathrm{eV})$. Such a strong TC-MnO interaction was achieved due to the interfacial O-Mn bonds. Potentially, these bonds may provide the channels for electron transfer from MI-excited $\mathrm{MnO}$ to TC, which plays an essential role in degradation. Such a hypothesis was confirmed by the calculated local density of states (LDOSs) as shown in Figure 9c, in which TC and MnO have several states (highlighted by empty and solid stars) that overlap around the Femi energy (dashed line in Figure 9c). From the calculated HOMO and LUMO, labelled in Figure $9 \mathrm{~d}$, the frontier orbit close to the Femi energy overwhelmingly contributed by the O-rich side, which has a strong interaction with the MnO clusters as shown in Figure 9b. Overall, both CNTs and $\mathrm{MnO}$ play key roles in degradation while the $\mathrm{MnO}$ layer enhances the TC-catalyst interaction through O-Mn bonding, both of which contribute to the degradation of TC.

(a)
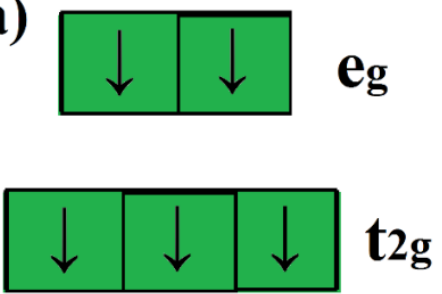

(c)

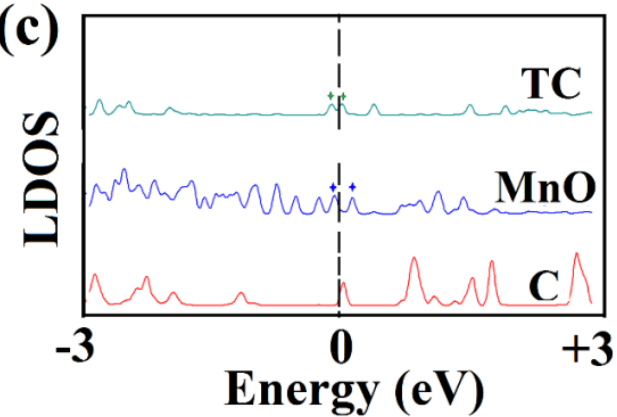

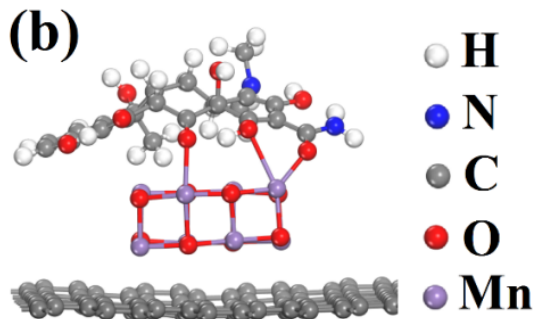

(d)

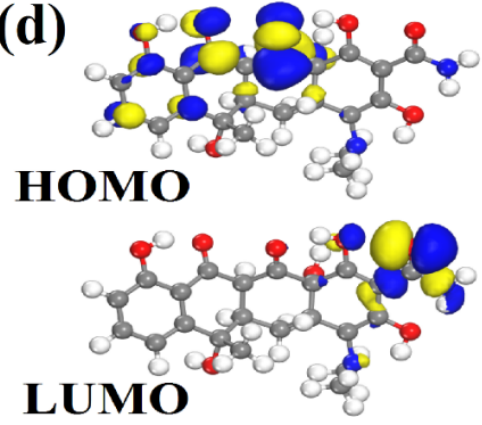

Figure 9. Theoretical calculations. Schematic 3d-orbitals splitting under the octahedral field (a); optimized TC/MnO/graphene structure (b); calculated local density of states (c); and calculated frontier orbitals of TC (d).

\section{Materials and Methods}

\subsection{Reagents}

$\mathrm{Mn}(\mathrm{Ac})_{2} \bullet 4 \mathrm{H}_{2} \mathrm{O}$ and $\mathrm{HNO}_{3}$ were bought from Beijing Chemical Industry Corporation (Beijing, China). Multi-walled carbon nanotube was obtained from Aladdin industries (Shanghai, China). Ethyl alcohol, Pure (200 proof, HPLC/spectrophotometric), was bought from Sigma-Aldrich (Sigma-Aldrich Canada Co., Oakville, Ontario, Canada) and TC (98 wt.\% purity) was bought from Hefei Bomei Biological Corporation (Hefei, China). Manganese ion standard solution for ICP testing, benzoquinone (BQ), and isopropanol (IPA) were obtained from Beijing Chemical Industry Corporation (Beijing, China). The above reagents were of analytical grade, which could be used directly.

\subsection{Synthesis of $\mathrm{MnO} / \mathrm{CNTS}$}

The synthesis of $\mathrm{MnO} / \mathrm{CNTs}$ involves three steps. First, the dried CNTs were dispersed in a concentrated nitric acid solution and sonicated. The mixture was refluxed at $120^{\circ} \mathrm{C}$ for $6 \mathrm{~h}$ to obtain oxidized CNTs. The synthesis of manganese hydroxy acetic acid/CNTs (Mn(Ac)OH/CNTs) was as follows: $40 \mathrm{mg} \mathrm{Mn}(\mathrm{Ac})_{2} \bullet 4 \mathrm{H}_{2} \mathrm{O}, 25 \mathrm{mg}$ oxidized CNTs, and $30 \mathrm{~mL}$ pure ethanol were added into a 
50-mL flask with three necks to form a uniformly dispersed solution after sonication. The sample was refluxed for $6 \mathrm{~h}$ at $80^{\circ} \mathrm{C}$. After cooling to room temperature, the sample was washed with alcohol, dried at $60{ }^{\circ} \mathrm{C}$ for $12 \mathrm{~h}$. Lastly, the precursor was calcined at $500{ }^{\circ} \mathrm{C}$ for $2 \mathrm{~h}$ in an argon atmosphere to obtain $\mathrm{MnO} / \mathrm{CNTs}$ composite.

\subsection{Microwave Experiment}

Microwave-induced catalytic degradation experiments were performed in a microwave reactor (Galanz, P70D20TPC6, Foshan, China) with a condensing device. First, $0.01 \mathrm{~g} \mathrm{MnO/CNTs} \mathrm{was} \mathrm{added}$ to a conical flask $\left(100 \mathrm{~mL}\right.$ ) together with $40 \mathrm{~mL}$ TC solution (primary concentration was $50 \mathrm{mg} \cdot \mathrm{L}^{-1}$ ), and the primary $\mathrm{pH}$ of the TC solution was approximately 6.5 to 6.9. After the reaction, the solution was cooled to room temperature and filtered for analysis. The $\mathrm{pH}$ of the equilibrium solution was adjusted only by the addition of an appropriate amount of concentrated $\mathrm{HCl}$ or $\mathrm{NaOH}$.

\subsection{Computational Investigation}

All geometric optimizations and energy calculations were performed within the framework of spin polarization density functional theory [54] with revised Perdew-Burke-Ernzerhof functional [55]. Specifically, valence electrons are described with plane waves having cut-off energies of $380 \mathrm{eV}$, along with the use of ultra-soft pesudopotentials for the core electrons of all elements other than hydrogen. The van der Waals interaction is considered to use the DFT-D3 scheme [56], as embedded in the VASP code [57]. During geometry optimizations, converges with a force under $0.02 \mathrm{eV} / \AA$ and energy changes under $10^{-4} \mathrm{eV}$ were achieved. K-space was sampled by $1 \times 1 \times 1$ Monkhorst-Pack k-points based on our tests.

Given that the CNTs used in our experiments have large diameters, the curvature effect is not remarkable; therefore, CNTs were modified with graphene. A small MnO cluster was introduced to the graphene basal plane, with a single TC adsorbed on MnO. Primary tests show that the TC-MnO interaction is stronger than TC-CNTs by $\sim 0.2 \mathrm{eV}$; thus, our analysis focused on TC-MnO-graphene.

\subsection{Methods of Analyses}

The crystal structure and diffraction peak intensities of the synthesized $\mathrm{Mn}(\mathrm{Ac}) \mathrm{OH} / \mathrm{CNTs}$ and $\mathrm{MnO} / \mathrm{CNTs}$ were identified by X-ray diffraction, operated under $40 \mathrm{kV}$ and $100 \mathrm{~mA}$ with $\mathrm{CuK} \alpha$ radiation (Bruker Scientific Instruments HongKong CO., HongKong, China). X-ray photoelectron spectroscopy (XPS) was used for measuring the chemical composition and valance of $\mathrm{MnO} / \mathrm{CNTs}$ (ULVAC-PHI.INC., Chigasaki City, Kanagawa, Japan). Transmission electron microscopy (TEM, JEOL Ltd., Akishima City, Tokyo, Japan) and energy dispersive X-ray spectroscopy were used to characterize the elemental distribution and morphology of MnO/CNTs. Prior to TEM characterization, the sample powder was dispersed in ethanol via sonication, and a drop of the sample was added to a carbon film supported by a copper grid and dried.

The removal efficiency of TC was evaluated by a UV-visible spectrophotometer (Shanghai, Chengyang Instrument Co., Ltd., China) as follows: The optical bandwidth is $2.0 \mathrm{~nm}$, the intermediate scanning speed is $1 \mathrm{~nm}$, the response time is $0.2 \mathrm{~s}$, and the scanning range is 250 to $450 \mathrm{~nm}$ (the wavelength of TC absorbance is $365 \mathrm{~nm}$ ). The total carbon content (TCC) of the solution was measured by a total organic carbon analyzer TOC (SHIMADZU-TOC-VCPH, Beijing, China) while the TC carbon content was tested using a UV-visible spectrophotometer. The contents of TC and its degradation products were determined by HPLC-MS (Thermo Fisher Scientific, Shanghai, China). To further determine the reaction products of TC after MICD (such as $\mathrm{NO}_{3}{ }^{-}$and $\mathrm{NH}_{4}{ }^{+}$), an ion chromatography (ICS-1100, Thermo Dionex, Shanghai, China) equipped with a conductivity detector, an eluent generator, a controller RFC-30, and an AS-DV automatic sampler was used. The eluent phase was $20 \mathrm{mmol} / \mathrm{L}$ $\mathrm{KOH}$ and the flow rate was $1.0 \mathrm{~mL} / \mathrm{min}$. The inhibition current was $50 \mathrm{~mA}$ and the column temperature was $30^{\circ} \mathrm{C}$. The concentration of manganese ions in TC solution before and after degradation was 
analyzed by inductively coupled plasma atomic emission spectrometry (ICP-AES, Thermo Fisher Scientific, ICAP 7600, Waltham, MA, USA).

\section{Conclusions}

In this work, we synthesized a novel catalytic material, $\mathrm{MnO} / \mathrm{CNTs}$, by simple reflux and calcination. The degradation mechanism of $\mathrm{MnO} / \mathrm{CNTs}$ was verified by theoretical calculation for the first time, indicating that the improvement of the microwave degradation performance was mainly attributed to the high-spin states of $\mathrm{Mn}(\mathrm{II})$, and the MnO layer enhanced the TC-catalyst interaction through $\mathrm{O}-\mathrm{Mn}$ bonding. As a microwave catalyst, $\mathrm{MnO} / \mathrm{CNTs}$ shows excellent catalytic ability, the removal amount of TC reached $185.7 \mathrm{mg} / \mathrm{g}$ in $10 \mathrm{~min}$ under MI, and the rate constant $(k=0.0530)$ was significantly larger than other antibiotic removal methods reported in the literature. The work also demonstrated that a series of intermediate compounds were produced during the MICD process before TC decomposed thoroughly to carbon dioxide, $\mathrm{NO}_{3}{ }^{-}$, and water. $\mathrm{MnO} / \mathrm{CNTs}$ are a good prospect in the environmental purification of organic contaminants, resulting in a simple preparation strategy, efficient catalysis, and good reusability.

Supplementary Materials: The following are available online at http://www.mdpi.com/2073-4344/9/11/911/s1, Figure S1: MS identification of bulk TC solution, Figure S2: MS identification of TC solution with 30 min MI treatment, separated by HPLC, Figure S3: MS identification of TC solution, isolated by preparative HPLC, with 10 min MI treatment using MnO/CNTs as microwave induced catalyst, Table S1: Mn ion concentration from ICP-AES results of TC solution and TC solution after degradation under MI with MnO/CNTs as catalyst, Table S2: Comparison of the degradation effects of different treating methods to remove antibiotics, Table S3: IC results of TC solution and TC solution after degradation under MI with MnO/CNTs as catalyst.

Author Contributions: Data curation, G.Y. and S.Q.; Investigation, Y.L.; Writing-review \& editing, T.L., G.L., L.L. and C.S.

Funding: This work was financially supported by Beijing Natural Science Foundation (2192048), National Natural Science Foundation of China (41831288), National Key R\&D Program of China (2017YFB0310704) and Fundamental Research Funds for the Central Universities (2652017338), Guangdong Innovation Research Team for Higher Education (2017KCXTD030), High-level Talents Project of Dongguan University of Technology (KCYKYQD2017017).

Conflicts of Interest: The authors declare no competing economic interests.

\section{References}

1. Liu, H.; Yang, Y.; Kang, J.; Fan, M.; Qu, J. Removal of tetracycline from water by Fe-Mn binary oxide. J. Environ. Sci. 2012, 24, 242-247. [CrossRef]

2. Daghrir, R.; Drogui, P.; Delegan, N.; E1, M.A. Electrochemical degradation of chlortetracycline using N-Doped $\mathrm{Ti} / \mathrm{TiO}_{2}$ photoanode under sunlight irradiations. Water Res. 2013, 47, 6801-6810. [CrossRef] [PubMed]

3. Shi, W.; Guo, F.; Yuan, S. In situ synthesis of Z-scheme $\mathrm{Ag}_{3} \mathrm{PO}_{4} / \mathrm{CuBi}_{2} \mathrm{O}_{4}$ photocatalysts and enhanced photocatalytic performance for the degradation of tetracycline under visible light irradiation. Appl. Catal. B Environ. 2017, 209, 720-728. [CrossRef]

4. Liu, X.; Xu, D.; Zhang, L. Fabrication of octahedral Cu@graphitic carbon cage complex porous structures and their microwave-driven catalytic activity. ACS Sustain. Chem. Eng. 2017, 9, 7800-7811. [CrossRef]

5. Baquero, F.; Martinez, J.L.; Canton, R. Antibiotics and antibiotic resistance in water environments. Curr. Opin. Biotechnol. 2008, 19, 260-265. [CrossRef] [PubMed]

6. Andreozzi, R.; Raffaele, M.; Nicklas, P. Pharmaceuticals in stp effluents and their solar photodegradation in aquatic environment. Chemosphere 2003, 50, 1319-1330. [CrossRef]

7. Sumpter, J.P.; Johnson, A.C. Lessons from endocrine disruption and their application to other issues concerning trace organics in the aquatic environment. Environ. Sci. Technol. 2005, 39, 4321-4332. [CrossRef]

8. Shi, Y.J.; Wang, X.H.; Qi, Z.; Diao, M.H.; Gao, M.M.; Xing, S.F.; Wang, S.G.; Zhao, X.C. Sorption and biodegradation of tetracycline by nitrifying granules and the toxicity of tetracycline on granules. J. Hazard. Mater. 2011, 191, 103-109. [CrossRef] 
9. Oturan, N.; Wu, J.; Zhang, H.; Sharma, V.K.; Oturan, M.A. Electrocatalytic destruction of the antibiotic tetracycline in aqueous medium by electrochemical advanced oxidation processes: Effect of electrode materials. Appl. Catal. B Environ. 2013, 140, 92-97. [CrossRef]

10. Ahmadiab, M.; Motlaghc, H.R.; Jaafarzadehab, N.; Mostoufid, A.; Saeedie, R.; Barzegarc, G.; Jorfiab, S. Enhanced photocatalytic degradation of tetracycline and real pharmaceutical wastewater using $\mathrm{MWCNT} / \mathrm{TiO}_{2}$ nano-composite. J. Environ. Manag. 2017, 186, 55-63.

11. Pargoletti, E.; Mostoni, S.; Rassu, G.; Pifferi, V.; Meroni, D.; Falciola, L.; Davoli, E.; Marelli, M. Cappelletti, G. Zn- vs Bi-based oxides for o-toluidine photocatalytic treatment under solar light. Environ. Sci. Pollut. Res. 2017, 24, 8287-8296. [CrossRef] [PubMed]

12. Palominos, R.A.; Mondaca, M.A.; Giraldo, A.; Peñuela, G.; Pérez-Moya, M.; Mansilla, H.D. Photocatalytic oxidation of the antibiotic tetracycline on $\mathrm{TiO}_{2}$ and $\mathrm{ZnO}$ suspensions. Catal. Today. 2009, 144, 100-105. [CrossRef]

13. Senthil Kumar, P.; Selvakumar, M.; Ganesh Babu, S.; Karuthapandian, S.; Chattopadhyay, S. CdO nanospheres: Facile synthesis and bandgap modification for the superior photocatalytic activity. Mater. Lett. 2005, 161, 45-48. [CrossRef]

14. Tambosi, J.; Sena, R.; Favier, M.; Gebhardt, W.; José, H.; Schröder, H.F.; Moreira, R. Removal of pharmaceutical compounds in membrane bioreactors (MBR) applying submerged membranes. Desalination 2010, 261, 148-156. [CrossRef]

15. Marcin, Z.; Magdalena, Z.; Marcin, D. Application of microwave radiation to biofilm heating during wastewater treatment in trickling filters. Bioresour. Technol. 2013, 127, 223-230.

16. Remya, N.; Lin, J.G. Current status of microwave application in wastewater treatment-a review. Chem. Eng. 2011, 166, 797-813. [CrossRef]

17. He, S.; Wang, G.; Lu, C.; Liu, J.; Wen, B.; Liu, H.; Guo, L.; Cao, M. Enhanced wave absorption of nanocomposites based on the synthesized complex symmetrical CuS nanostructure and poly(vinylidene fluoride). J. Mater. Chem. A 2013, 15, 4685-4692. [CrossRef]

18. Liu, X.; Xu, D.; Zhang, D.; Zhang, G.; Zhang, L. Superior performance of 3D Co-Ni bimetallic oxides for catalytic degradation of organic dye: Investigation on the effect of catalyst morphology and catalytic mechanism. Appl. Catal. B Environ. 2016, 186, 193-203. [CrossRef]

19. Ai, Z.; Wang, Y.; Mi, X.; Zhang, L.; Qiu, J. Microwave-induced catalytic oxidation of RhB by a nanocomposite of $\mathrm{Fe} @ \mathrm{Fe}_{2} \mathrm{O}_{3}$ core-shell nanowires and carbon nanotubes. J. Phys. Chem. C 2008, 112, 9847-9853. [CrossRef]

20. Wang, C.; Fu, J.; Zhang, Y.; Zhao, H.; Wei, X.; Zhang, R. Microhydrangeas with a high ratio of low valence $\mathrm{MnO}_{\mathrm{x}}$ are capable of extremely fast degradation of organics. Chem. Commun. 2018, 54, 7330-7333. [CrossRef]

21. Ding, S.; Wen, H.; Yang, S.; Mao, D.; Yuan, J.; Dai, Y. Degradation of Azo dye direct black BN based on adsorption and microwave-induced catalytic reaction. Environ. Sci. Eng. 2018, 12, 71-83. [CrossRef]

22. He, H.; Yang, S.; Yu, K.; Ju, Y.; Sun, C.; Wang, L. Microwave induced catalytic degradation of crystal violet in nano-nickel dioxide suspensions. J. Hazard. Mater. 2010, 173, 393-400. [CrossRef] [PubMed]

23. Wang, X.; Lv, G.; Liao, L.; Wang, G. Manganese oxide-an excellent microwave absorbent for the oxidation of methylene blue. RSC Adv. 2015, 5, 55595-55601. [CrossRef]

24. Gu, W.; Lv, G.; Liao, L.; Yang, C.; Liu, H.; Nebendahl, I.; Li, Z. Fabrication of Fe-doped birnessite with tunable electron spin magnetic moments for the degradation of tetracycline under microwave irradiation. J. Hazard. Mater. 2017, 338, 428-436. [CrossRef] [PubMed]

25. Wen, F.; Fang, Z.; Liu, Z. Investigation on microwave absorption properties for multiwalled carbon nanotubes/Fe/Co/Ni nanopowders as lightweight absorbers. J. Phys. Chem. C 2011, 115, 14025-14030. [CrossRef]

26. Lu, M.; Cao, M.; Chen, Y.; Cao, W.; Liu, J.; Shi, H.; Zhang, D.; Wang, W.; Yuan, J. Multiscale assembly of grape-like ferroferric oxide and carbon nanotubes: A smart absorber prototype varying temperature to tune intensities. ACS Appl. Mater. Interfaces 2015, 7, 19408-19415. [CrossRef]

27. Yin, Y.; Liu, X.; Wei, X.; Li, Y.; Nie, X.; Yu, R.; Shui, J. Magnetically aligned Co-C/MWCNTs composite derived from mwcnt-interconnected zeolitic imidazolate frameworks for a lightweight and highly efficient electromagnetic wave absorber. ACS Appl. Mater. Interfaces 2017, 9, 30850-30861. [CrossRef]

28. Duan, Y.; Xiao, Z.; Yan, X.; Gao, Z.; Tang, Y.; Hou, L.; Li, Q.; Ning, G.; Li, Y. Enhanced electromagnetic microwave absorption property of peapod-like MnO@carbon nanowires. ACS Appl. Mater. Interfaces 2018, 10, 40078-40087. [CrossRef] 
29. Yin, Y.; Liu, X.; Wei, X.; Yu, R.; Shui, J. Porous CNTs/Co composite derived from zeolitic imidazolate framework: A lightweight, ultrathin and highly efficient electromagnetic wave absorber. ACS Appl. Mater. Interfaces 2016, 8, 34686-34698. [CrossRef]

30. Li, N.; Huang, G.; Li, Y.; Xiao, H.; Feng, Q.; Hu, N.; Fu, S. Enhanced microwave absorption performance of coated carbon nanotubes by optimizing the $\mathrm{Fe}_{3} \mathrm{O}_{4}$ nanocoating structure. ACS Appl. Mater. Interfaces 2017, 9, $2973-2983$. [CrossRef]

31. Shin, H.H.; Yeon, G.J.; Choi, H.K.; Park, S.M.; Lee, K.S.; Kim, Z.H. Frequency-Domain proof of the existence of atomic-scale SERS hot-spots. Nano Lett. 2018, 18, 262-271. [CrossRef] [PubMed]

32. Liu, S.; Mei, L.; Liang, X.; Liao, L.; Lv, G.; Ma, S.; Lu, S.; Abdel, A.; Xi, K. Anchoring $\mathrm{Fe}_{3} \mathrm{O}_{4}$ nanoparticles on carbon nanotube for microwave-induced catalytic degradation of antibiotics. ACS Appl. Mater. Interfaces 2018, 10, 29467-29475. [CrossRef] [PubMed]

33. Zhang, Z.; Yang, Y.; Sun, L.; Liu, R. Direct conversion of metal-polyphenolic coordination assembly to MnOx-Carbon nanocomposites for catalytic degradation of methylene blue. Mater. Lett. 2018, 221, 97-100. [CrossRef]

34. Chen, S.; Chen, D.; Wang, W.; Quan, H.; Luo, X.; Guo, L. rGO-stabilized MnO/N-doped carbon nanofibers for efficient removal of $\mathrm{Pb}(\mathrm{II})$ ion and catalytic degradation of methylene blue. J. Mater. Sci. 2017, 52, 5117-5132. [CrossRef]

35. Mettela, G.; Bhogra, M.; Waghmare, U.V.; Kulkarni, G.U. Ambient stable tetragonal and orthorhombic phases in penta-twinned bipyramidal au microcrystals. J. Am. Chem. Soc. 2015, 137, 3024-3030. [CrossRef]

36. Chen, J.; Zhang, H.; Liu, P.; Li, Y.; Liu, X.; Li, G.; Wong, K.; An, W.; Zhao, H. Cross-linked ZnIn ${ }_{2} \mathrm{~S}_{4} / \mathrm{rGO}$ composite photocatalyst for sunlight-driven photocatalytic degradation of 4-nitrophenol. Appl. Catal. B Environ. 2015, 168, 266-273. [CrossRef]

37. Wang, T.; Jiang, Z.; An, T.; Li, G.; Zhao, H.; Wong, P.K. Enhanced visible light-driven photocatalytic bacterial inactivation by ultrathin carbon-coated magnetic cobalt ferrite nanoparticles. Environ. Sci. Technol. 2018, 52, 4774-4784. [CrossRef]

38. Daghrir, R.; Drogui, P.; El Khakani, M.A. Photoelectrocatalytic oxidation of chlortetracycline using $\mathrm{Ti} / \mathrm{TiO} \mathrm{O}_{2}$ photo-anode with simultaneous $\mathrm{H}_{2} \mathrm{O}_{2}$ production. Electrochim. Acta 2013, 87, 18-31. [CrossRef]

39. Sun, Y.; Hu, X.; Luo, W.; Huang, Y. Porous carbon-modified MnO disks prepared by a microwave-polyol process and their superior lithium-ion storage properties. J. Mater. Chem. 2012, 22, 19190-19195. [CrossRef]

40. Xiao, Y.; Xua, C.; Wang, P.; Fang, H.; Sun, X.; Ma, F.; Pei, Y.; Zhen, L. Encapsulating MnO nanoparticles within foam-like carbon nanosheet matrix for fast and durable lithium storage. Nano Energy 2018, 50, 675-684. [CrossRef]

41. Zhang, L.; Liu, X.; Guo, X.; Su, M.; Xu, T.; Song, X. Investigation on the degradation of brilliant green induced oxidation by $\mathrm{NiFe}_{2} \mathrm{O}_{4}$ under microwave irradiation. Chem. Eng. J. 2011, 173, 734-742. [CrossRef]

42. Chen, J.; Xue, S.; Song, Y.T.; Shen, M.L.; Zhang, Z.H.; Yuan, T.X.; Tian, F.Y. Dionysiou, D.D. Microwave-induced carbon nanotubes catalytic degradation of organic pollutants in aqueous solution. J. Hazard. Mater. 2016, 310, 226-234. [CrossRef] [PubMed]

43. Lv, G.C.; Xing, X.B.; Liao, L.B.; An, P.F.; Yin, H.; Mei, L.F.; Li, Z. Synthesis of birnessite with adjustable electron spin magnetic moments for the degradation of tetracycline under microwave induction. Chem. Eng. J. 2017, 326, 329-338. [CrossRef]

44. Colaizzi, J.L.; Klink, P.R. pH-Partition behavior of tetracyclines. J. Pharm. Sci. 1969, 58, 1184-1189. [CrossRef] [PubMed]

45. Sassman, S.A.; Lee, L.S. Sorption of three tetracyclines by several soils: Assessing the role of $\mathrm{pH}$ and cation exchange. Environ. Sci. Technol. 2005, 39, 7452-7459. [CrossRef]

46. Liu, M.; Lv, G.; Mei, L.; Wang, X.; Xing, X.; Liao, L. Degradation of tetracycline by birnessite under microwave irradiation. Adv. Mater. Sci. Eng. 2015, 2014,1-5. [CrossRef]

47. Johnston, H.J.; Hutchison, G.R.; Christensen, F.M.; Peters, S.; Hankin, S.; Aschberger, K.; Stone, V. A critical review of the biological mechanisms underlying the in vivo and in vitro toxicity of carbon nanotubes: The contribution of physico-chemical characteristics. Nanotoxicology 2010, 4, 207-246. [CrossRef]

48. Wang, W.; Fang, J.; Shao, S.; Lai, M.; Lu, C. Compact and uniform $\mathrm{TiO}_{2} @ g-\mathrm{C}_{3} \mathrm{~N}_{4}$ core-shell quantum heterojunction for photocatalytic degradation of tetracycline antibiotics. Appl. Catal. B Environ. 2017, 217, 57-64. [CrossRef] 
49. An, T.; An, J.; Gao, Y.; Li, G.; Fang, H.; Song, W. Photocatalytic degradation and mineralization mechanism and toxicity assessment of antivirus drug acyclovir: Experimental and theoretical studies. Appl. Catal. B Environ. 2015, 164, 279-287. [CrossRef]

50. Huang, Y.; Fang, Y.; Li, R.; Sun, H.; Zhao, X.; Liu, S. The degradation of tetracycline in a photo-electro-fenton system. Chem. Eng. J. 2013, 231, 441-448.

51. Zhu, Z.; Yu, Y.; Huang, H.; Yao, X.; Dong, H.; Liu, Z.; Yan, Y.; Li, C.; Huo, P. Microwave-hydrothermal synthesis of a novel, recyclable and stable photocatalytic nanoreactor for recognition and degradation of tetracycline. Catal. Sci. Technol. 2017, 7, 4092-4104. [CrossRef]

52. Li, J.; Zhou, M.; Ye, Z.; Wang, H.; Ma, C.; Huo, P.; Yan, Y. Enhanced photocatalytic activity of g- $\mathrm{C}_{3} \mathrm{~N}_{4}-\mathrm{ZnO} / \mathrm{HNTs}$ composite heterostructure photocatalysts for degradation of tetracycline under visible light irradiation. RSC Adv. 2015, 5, 91177-91189. [CrossRef]

53. Wang, K.; Zhang, G.; Li, J.; Li, Y.; Wu, X. 0D/2D Z Scheme heterojunctions of bismuth tantalate quantum dots/ultrathin $\mathrm{g}-\mathrm{C}_{3} \mathrm{~N}_{4}$ nanosheets for highly efficient visible light photocatalytic degradation of antibiotics. ACS Appl. Mater. Interfaces 2017, 9, 43704-43715. [CrossRef] [PubMed]

54. Kohn, W.; Sham, L.J. Self-Consistent equations including exchange and correlation effects. Phys. Rev. 1965, 140, A1133-A1138. [CrossRef]

55. Hammer, B.; Hansen, L.B.; Nørskov, J.K. Improved adsorption energetics within density-functional theory using revised perdew-burke-ernzerhof functionals. Phys. Rev. B 1999, 59, 7413-7421. [CrossRef]

56. Goerigk, L.; Grimme, S. A general database for main group thermochemistry, kinetics, and noncovalent interactions-assessment of common and reparameterized (meta-)gga density functionals. J. Chem. Theory Comput. 2010, 6, 107-126. [CrossRef]

57. Kresse, G.; Joubert, D. From ultrasoft pseudopotentials to the projector augmented-wave method. Phys. Rev. B 1999, 59, 1758-1775. [CrossRef]

(C) 2019 by the authors. Licensee MDPI, Basel, Switzerland. This article is an open access article distributed under the terms and conditions of the Creative Commons Attribution (CC BY) license (http://creativecommons.org/licenses/by/4.0/). 